\title{
The Effect of Fluoroscopy Control on Cannulation Rate and Fluoroscopy Time in Endoscopic Retrograde Cholangiopancreatography Training
}

\author{
Raymond E. Kim', Lance T. Uradomo', Grace E. Kim², John D. Morris', Eric M. Goldberg', Peter E. Darwin \\ ${ }^{1}$ Division of Gastroenterology and Hepatology, University of Maryland School of Medicine, Baltimore, MD; \\ ${ }^{2}$ Department of Internal Medicine, University of Maryland Medical Center, Baltimore, MD, USA
}

Background/Aim: Endoscopic retrograde cholangiopancreatography (ERCP) training requires varying degrees of staff assistance regarding operation of the fluoroscopy machine via a foot pedal. Efficiency is important to acquire during this training due to radiation risks. In this study, we evaluate the effect of controlling endoscopy and fluoroscopy unit on duct cannulation rates (CRs) and total fluoroscopy time (FT) for fellows in training.

Methods: 204 patients undergoing ERCP were randomized to one of two groups: 1) "Endoscopist Driven" group in which the endoscopist controlled the foot pedal for fluoroscopy, and 2) "Assistant Driven" group in which attending or fellow controlled the foot pedal while the other team member controlled the endoscope. Various measures including selective duct CR and total FT were recorded.

Results: There was no significant difference in mean procedure duration between the two groups ( 32 minutes vs. 33 minutes, $p=0.70$ ). There was also no statistically significant difference in CR $(83.7 \%$ vs. $77.4 \%, p=0.25)$ or FT (3.27 minutes vs. 3.54 minutes, $p=0.48$ ).

Conclusions: ERCP is a technically challenging procedure which requires extensive supervision. This study demonstrates that CR and FT are not affected by who controls the fluoroscopy.

Korean J Pancreas Biliary Tract 2021;26(1):43-48

Keywords: Endoscopic retrograde cholangiography, Education, Instrumentation,

Fluoroscopy

\author{
Received Jun. 30, 2020 \\ Revised Sep. 6, 2020 \\ Accepted Sep. 6, 2020
}

Corresponding author : Grace E. Kim

Department of Internal Medicine, University of

Maryland Medical Center, 22 South Greene St.,

Baltimore, MD 21201, USA

Tel: +1-240-750-0466

Fax. +1-276-883-6803

E-mail: Grace.kim@som.umaryland.edu

ORCID: https://orcid.org/0000-0001-7406-6684

This is an Open Access article distributed under the terms of the Creative Commons Attribution Non-Commercial License (http:// creativecommons.org/licenses/by-nc/3.0/) which permits unrestricted non-commercial use, distribution, and reproduction in any medium, provided the original work is properly cited.

Copyright $@ 2021$ by The Korean Journal of Pancreas and Biliary Tract

\section{INTRODUCTION}

As gastroenterology (GI) fellows learn to perform endoscopic retrograde cholangiography, there are varying degrees of staff assistance regarding operation of the fluoroscopy machine via a foot pedal. Due to its complexity, in the United States, endoscopic retrograde cholangiopancreatography (ERCP) skills are most commonly learned during an additional year of interventional or advanced GI fellowship that occurs after completion of the 3-year GI fellowship. It is not known whether allowing the fellow to control both the scope and fluoroscopy unit affects the procedure outcome or fluoroscopy time (FT). We examine the effect of controlling both the endoscope and the fluoroscopy unit on selected duct cannulation rates (CRs) and total FT for fellows in an interventional GI fellowship program. 


\section{METHODS}

\section{Patients}

Patients between the ages of 18 and 92 who presented to a single university-based endoscopy unit for ERCP between January 2013 and September 2013 were eligible for enrollment. Any inpatient or outpatient having an ERCP performed at the University of Maryland Gastroenterology Division was offered entrance into the study. Patients excluded from the study were those who did not agree to participate or required special requirements for minimal fluoroscopy (i.e. pregnancy). Patient's age, race, and gender were recorded. The study was approved by the Institutional Review Board of the University of Maryland, Baltimore. A written informed consent was obtained from all participants.

\section{Procedures}

This is a single-center simple randomized study. X-ray settings were selected per case based on random selection by sealed envelopes pre procedure. Patients were randomized to one of two groups: 1) "Endoscopist Driven" and 2) "Assistant Driven." In the "Endoscopist Driven" group, the endoscopist controlled the foot pedal to operate the fluoroscopy machine for the duration of the procedure, regardless of whether the attending or fellow was controlling the endoscope. In the "Assistant Driven" group, either the attending or fellow controlled the fluoroscopy machine while the other team member controlled the endoscope. The endoscopist in all cases was initially the fellow who was assigned to the case. However, if cannulation was not successful by the fellow, the attending physician then became the Endoscopist of the case. All procedures utilized the same fluoroscopy equipment, OEC series 9600 C-arm (OECMedical, Salt Lake City, UT, USA).

\section{Data collection}

This was a prospective randomized trial approved by the Institutional Review Board at the University of Maryland
Medical Center (approval number HP-00054764). Procedure data included endoscopist, assistants, total procedure duration (from endoscope insertion to removal), total FT, time of staff controlling endoscope, type of procedure, indication for procedure, and immediate complications. In addition, the following technical components were recorded: whether the procedure was successful, failed, or not attempted; whether the attending or fellow obtained cannulation of the desired duct; and the intervention attempted, which include previous sphincterotomy, pancreatography, cholangiography, cholangioscopy, bile duct stent insertion, pancreatic duct stent insertion, biliary sphincterotomy, precut septotomy, needle knife, pancreatic sphincterotomy, lithotripsy, balloon sweep (non stone), balloon stone extraction, basket stone extraction, dilation, cyst drainage, manometry, ductal biopsy, cytology brushing, stent removal, therapy for bleeding, and ampullectomy. A scoring system rated cannulation of the desired duct as easy (score $1,<5$ touches), moderate (score 2, 6-15 touches), or difficult (score 3,>15 touches). The primary outcomes were total FT and successful fellow cannulation. Secondary outcomes included total procedure time and complications.

\section{Statistical analysis}

A sample-size calculation identified a requirement of 100 procedures per group to measure a 20\% difference in mean FT with a power of 0.80 and a significance level of 0.05 (alpha $=0.05$, two-sided). Mean FT (and 95\% confidence intervals $[\mathrm{CI}])$ is expressed in seconds. Parametric data including FT were compared by using the $t$-test. Dichotomous variables including CR were analyzed with the Pearson $X^{2}$ test. We also performed multivariate multilevel logistic regression with each therapeutic intervention as variables including pancreatograms, biliary stenting, dilation, and intraductal biopsies. A $p$-value of $<0.05$ was considered statistically significant. Analyses were performed using SAS 9.1 software (SAS Institute, Cary, NC, USA) and Excel 2016 (Microsoft, Seattle, WA, USA). 


\section{RESULTS}

\section{Patient characteristics}

A total of 204 patients were enrolled, 97 in the "Endoscopist Driven" group and 107 in the "Assistant Driven” group (Table 1). There was no difference between the groups by age or sex.

\section{Procedure characteristics}

ERCPs were performed under the supervision of three

Table 1. Patient and procedure characteristics

\begin{tabular}{|c|c|c|c|}
\hline & $\begin{array}{c}\text { Endoscopist } \\
\text { Driven } \\
\text { Fluoroscopy }\end{array}$ & $\begin{array}{c}\text { Assistant } \\
\text { Driven } \\
\text { Fluoroscopy }\end{array}$ & $p$-values \\
\hline Total subjects & 97 & 107 & \\
\hline Mean age & 59.51 & 57.65 & 0.475 \\
\hline Female & $52(53.6)$ & $59(55.1)$ & 0.826 \\
\hline \multicolumn{4}{|l|}{ Endoscopist } \\
\hline 1 & $43(44.3)$ & $34(32.0)$ & 0.138 \\
\hline 2 & $37(38.1)$ & $44(41.5)$ & \\
\hline 3 & $17(17.5)$ & $28(26.4)$ & \\
\hline \multicolumn{4}{|l|}{ Long and short wire } \\
\hline Long wire & $43(44.3)$ & $34(32.0)$ & 0.072 \\
\hline Short wire & $54(55.6)$ & $72(62.0)$ & \\
\hline \multicolumn{4}{|l|}{ Intervention attempted } \\
\hline Previous sphincterotomy & $31(31.9)$ & $46(42.9)$ & 0.104 \\
\hline Cholangiogram & $90(92.7)$ & $97(90.6)$ & 0.562 \\
\hline Pancreatogram & $16(16.4)$ & $21(19.6)$ & 0.104 \\
\hline Cholangioscopy & 0 & $1(0)$ & 0.342 \\
\hline Bile duct stent & $37(38.1)$ & $43(40.1)$ & 0.765 \\
\hline Pancreatic duct stent & $25(25.7)$ & $19(17.7)$ & 0.164 \\
\hline Biliary sphincterotomy & $53(54.6)$ & $59(55.1)$ & 0.942 \\
\hline Precut septotomy & $3(0)$ & $9(0)$ & 0.106 \\
\hline Needle-knife & $3(0)$ & $9(0)$ & 0.106 \\
\hline Dilation & $18(18.5)$ & $28(26.1)$ & 0.193 \\
\hline Ductal biopsy & $8(0)$ & $16(1)$ & 0.137 \\
\hline Mean procedure time (min) & 32 & 33 & 0.7 \\
\hline $\begin{array}{l}\text { Mean cannulation } \\
\text { difficulty }\end{array}$ & 1.59 & 1.7 & 0.49 \\
\hline
\end{tabular}

Values are presented as number (\%). attending gastroenterologists. There was no significant difference in the distribution of the "Endoscopist Driven" group and the "Assistant Driven" group among the endoscopists $(p=0.13)$. The mean procedure duration was 32 minutes and there was no significant difference between the two groups (32 minutes vs. 33 minutes, $p=0.70$ ).

The ERCPs were also performed with two different wire systems. One attending physician exclusively used a long Olympus (Olympus America, Center Valley, PA, USA) wire system while the other two attending physicians used a short Boston Scientific (Boston Scientific, Marlborough, MA, USA) wire system. Both the long and short wire systems used wireguided cannulation for selective cannulation. There was no significant difference in the distribution of the long and short wire system procedures between the "Endoscopist Driven" and the "Assistant Driven" groups.

There was a total of four trainees who participated in this study. Of the 204 cases, 147 procedures were done by the trainees who had performed more than 100 ERCP cases, and the remaining 57 procedures were performed by trainees who had performed 50 to 100 cases. Cholangiography was performed in $91 \%$ of the cases. Biliary sphincterotomy (54.9\%) and bile duct stent placement (39.2\%) were frequently performed. There was no difference in degree of cannulation difficulty between the groups.

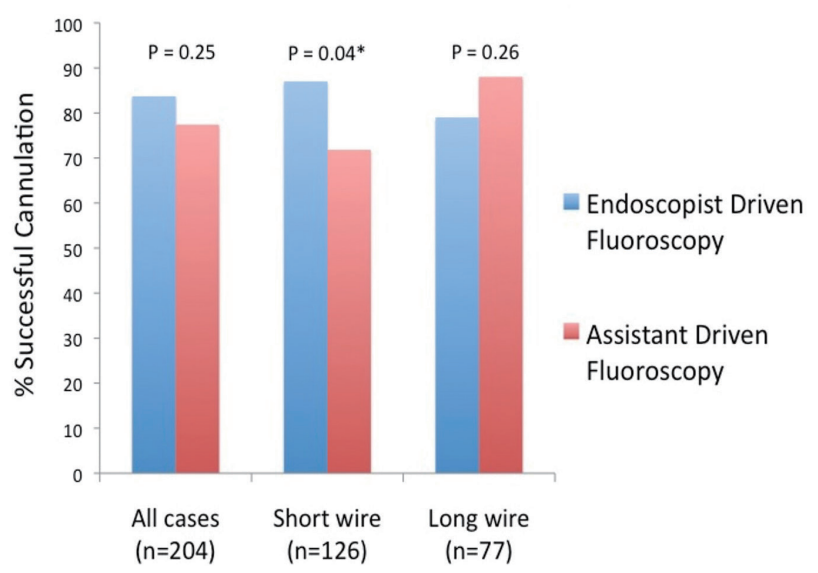

Fig. 1. Successful cannulation rate between Endoscopist Driven and Assistant Driven groups. 


\section{The ERCP}

1) Bivariate analysis

(1) CR

The overall trainee CR was $80.4 \%$. The CR in the Endos- copist Driven group was $83.7 \%$ and in the Assistant Driven group was $77.4 \%$ ( $p=0.25$ ) (Fig. 1). There was no significant difference in trainee CR between the long wire system cases $(83 \%)$ and the short wire system cases $(78 \%, p=0.39)$.

Sub-group analysis of cases performed with the short wire system showed a significantly higher CR in the Endoscopy

Table 2. Bivariate analysis of fluoroscopy between Endoscopist Driven and Assistant Driven groups

\begin{tabular}{|c|c|c|c|c|}
\hline & $\mathrm{N}$ & Mean fluoroscopy time (min) & $95 \% \mathrm{Cl}$ & $p$-values \\
\hline Endoscopist driven & 97 & 3.27 & $2.76-3.8$ & 0.48 \\
\hline Assistant driven & 107 & 3.54 & $3.01-4.07$ & \\
\hline Long wire & 77 & 3.45 & & 0.89 \\
\hline Short wire & 126 & 3.4 & & \\
\hline Malignant biliary stricture & & & & $<0.001$ \\
\hline Yes & 38 & 4.96 & & \\
\hline No & 166 & & & \\
\hline Cannulation difficulty & & & & $<0.001$ \\
\hline Easy cannulation & 82 & 2.06 & & \\
\hline Moderate, difficult, or failed cannulation & 62 & 4.75 & & \\
\hline Sex & & & & 0.68 \\
\hline Male & 92 & 3.5 & & \\
\hline Female & 110 & 3.35 & & \\
\hline Pancreatogram & & & & 0.003 \\
\hline Yes & 36 & 4.69 & & \\
\hline No & 168 & 3.14 & & \\
\hline Bile duct stent & & & & 0.01 \\
\hline Yes & 24 & 4.64 & & \\
\hline No & 179 & 3.25 & & \\
\hline Dilation & & & & $<0.001$ \\
\hline Yes & 46 & 5.01 & & \\
\hline No & 158 & 2.95 & & \\
\hline Pre-cut septotomy & & & & 0.21 \\
\hline Yes & 12 & 4.41 & & \\
\hline No & 192 & 3.35 & & \\
\hline Lithotripsy & & & & 0.01 \\
\hline Yes & 12 & 6.51 & & \\
\hline No & 191 & 3.21 & & \\
\hline Stone extraction (balloon) & & & & 0.19 \\
\hline Yes & 90 & 3.14 & & \\
\hline No & 114 & 3.62 & & \\
\hline Intraductal biopsies & & & & 0.004 \\
\hline Yes & 24 & 5.41 & & \\
\hline No & 180 & 3.14 & & \\
\hline
\end{tabular}

$\mathrm{Cl}$, confidence interval. 
Driven group compared to the Assistant Driven group (87\% vs. $71.8 \%, p=0.04)$. Sub-group analysis of cases with long wire system showed no significant difference between the two study groups (Endoscopist 79\% vs. Assistant 88\%,p=0.26) (Fig. 1).

There was no statistically significant difference in trainee CR between trainees who had more than 100 cases of ERCP experience $(82 \%)$ those who had between 50 and 100 cases $(77 \%, p=0.49)$.

CR was dramatically higher in cases where there was a prior sphincterotomy (70\% without vs. $97 \%$ with prior sphincterotomy, $p<0.001)$. Trainee cannulation was lower in cases with diagnoses of bile leak (82 without vs. 60\% with bile leak, $p=0.04$ ), pancreas divisum ( 80 without vs. 33\% with divisum, $p=0.04$ ), and ampullary adenoma (82 without vs. $0 \%$ with ampullary adenoma, $p<0.001)$. Multivariate logistic analysis including these factors failed to show a significant association between CR and study group $(p=0.24)$.

\section{2) $F T$}

On bivariate analysis, there was no statistically significant difference in FT between the Endoscopist Driven versus Assistant Driven groups (Table 2). The mean FT for Endoscopist Driven group was 3.27 minutes (95\% CI 2.76-3.8), with 3.54 minutes (95\% CI 3.01-4.07, $p=0.48$ ) for Assistant Driven group. Mean FT was greater in cases with the diagnosis of malignant biliary stricture (3.05 vs. 4.96 minutes; $p<0.001)$. There was no statistically significant difference in FT between the long wire system cases (3.45 minutes) and short wire system cases (3.4 minutes, $p=0.89$ ).

Subgroup analysis of the cases with only the long wire system showed a favorable statistical trend in a decrease in FT in the Endoscopist Driven group (3.05 minutes) compared to the Assistant Driven group (3.92 minutes, $p=0.076$ ). This trend in FT was not observed in the cases with the short wire system.

\section{3) Multivariate analysis}

Pancreatogram, biliary stenting, dilation, and intraductal biopsies were found on multivariate analysis to be the therapies independently associated with longer FT. When these variables were used in a step wise multivariate linear analysis, the study group was not significantly associated with prolonged FT $(p=0.96)$.

\section{DISCUSSION}

ERCP is a technically challenging procedure which requires substantial training with extensive supervision, as well as ample amount of hands-on experience to develop expertise for performing the procedure safely and effectively. ${ }^{1-6}$ Watkins et al. ${ }^{3}$ reported the $85 \%$ level of selective cannulation may be reached after at least 100 procedures. Jowell et al. ${ }^{1}$ found at least 180 to 200 supervised procedures were recommended for a trainee to achieve an overall 80\% likelihood of successful ERCP cannulation.Verma et al. ${ }^{5}$ published that the consistent achievement of more than $80 \%$ success rate with native papillary anatomy should become a standard for ERCP training.

Radiation exposure is well known to increase risk of future cancer $^{7-11}$; therefore, minimizing exposure to patients and staff is recommended. ${ }^{12-14}$ Radiation doses to patients during ERCP depend on many factors including patient size, difficulty of procedure, copper X-ray beam filtration, fluoroscopic loop review, last image hold, number of digital spots taken, pulse mode setting, magnification mode, and collimation, but the most controllable factor is FT. ${ }^{9,13,15}$

We opted to look at the effect that controlling both the endoscope and the fluoroscopy pedal has on total FT and selected duct CRs for trainees in an interventional GI fellowship. On bivariate analysis and step wise multivariate analysis, we found no significant difference in FT and fellow CR between Endoscopist Driven group and Assistant Driven group.

One of the limitations of the study was that the endoscopists were not blinded to the study group assignment, which was not possible by the study design. Another limitation in our study was that a limited number of fellows in different stages of training participated within a single institution.

In this study, we observed the effect of various measures of case complexity on FT. Mean FT was greater in cases with the diagnosis of malignant biliary stricture (3.05 vs. 4.96 minutes; 
$p<0.001)$. In addition, biliary stenting, dilation, and intraductal biopsies were found to be the therapies independently associated with longer FT on multivariate analysis. The CR was dramatically higher in cases where there was a prior sphincterotomy. Trainee cannulation was lower in cases with diagnoses of bile leak, pancreas divisum and ampullary adenoma.

In conclusion, during ERCP training, the ability of trainees to cannulate the desired duct and the amount of fluoroscopy used are affected by multiple factors; however, whether the fluoroscopy is controlled by the trainee or attending does not affect the cannulation outcome or FT.

\section{Conflicts of Interest}

The authors have no conflicts to disclose.

\section{REFERENCES}

1. Jowell PS, Baillie J, Branch MS, Affronti J, Browning $C L$, Bute BP. Quantitative assessment of procedural competence. A prospective study of training in endoscopic retrograde cholangiopancreatography. Ann Intern Med 1996;125:983-989.

2. Uradomo LT, Lustberg ME, Darwin PE. Effect of physician training on fluoroscopy time during ERCP. Dig Dis Sci 2006;51:909-914.

3. Watkins JL, Etzkorn KP, Wiley TE, DeGuzman L, Harig JM. Assessment of technical competence during ERCP training. Gastrointest Endosc 1996;44:411-415.

4. Kachaamy TA, Faigel DO. Improving ERCP quality and decreasing risk to patients and providers. Expert Rev Gastroenterol Hepato 2013;7:531-540
5. Verma D, Gostout CJ, Petersen BT, Levy MJ, Baron TH, Adler DG. Establishing a true assessment of endoscopic competence in ERCP during training and beyond: a single-operator learning curve for deep biliary cannulation in patients with native papillary anatomy. Gastrointest Endosc 2007;65:394-400.

6. Oztas E, Parlak E, Kucukay F, et al. The impact of endoscopic retrograde cholangiopancreatography education on radiation exposure to experienced endoscopist: 'trainee effect'. Dig Dis Sci 2012;57:11341143.

7. Preston DL, Pierce DA, Shimizu $Y$, et al. Effect of recent changes in atomic bomb survivor dosimetry on cancer mortality risk estimates. Radiat Res 2004;162:377-389.

8. Larkin CJ, Workman A, Wright RE, Tham TC. Radiation doses to patients during ERCP. Gastrointest Endosc 2001;53:161-164.

9. Jorgensen JE, Rubenstein JH, Goodsitt MM, Elta GH. Radiation doses to ERCP patients are significantly lower with experienced endoscopists. Gastrointest Endosc 2010;72:58-65.

10. Rodríguez-Perálvarez ML, Miñano-Herrrero JA, Hervás-Molina AJ, et al. Radio induced cancer risk during ERCP. Is it a real clinical problem?. Rev Esp Enferm Dig 2011;103:191-195.

11. Cohen RV, Aldred MA, Paes WS, et al. How safe is ERCP to the endoscopist?. Surg Endosc 1997;11:615-617.

12. Miller DL, Balter S, Noonan PT, Georgia JD. Minimizing radiationinduced skin injury in interventional radiology procedures. Radiology 2002;225:329-336.

13. Uradomo LT, Goldberg EM, Darwin PE. Time-limited fluoroscopy to reduce radiation exposure during ERCP: a prospective randomized trial. Gastrointest Endosc 2007;66:84-89.

14. Savides TJ. Reducing radiation risks during ERCP: less is more. Ann Gastroenterol 2012;25:279-280.

15. Martin CJ. A review of factors affecting patient doses for barium enemas and meals. Br J Radiol 2004;77:864-868. 